\title{
Oxidative Stress in the Heart of Rats Infected with Trypanosoma evansi
}

\author{
Matheus D. Baldissera',*, Carine de F. Souza², Cláudia M. Bertoncheli', Karine L. da Silveira', Thirssa H. Grando', \\ Bianca C. Z. Porto', Daniela B. R. Leal', Aleksandro S. Da Silva, Ricardo E. Mendes', Lenita M. Stefani3, \\ Silvia G. Monteiro ${ }^{1, *}$
}

'Department of Microbiology and Parasitology, Universidade Federal de Santa Maria (UFSM), Santa Maria, RS, Brazil; '2Department of Pharmacology and Physiology, Universidade Federal de Santa Maria (UFSM), Santa Maria, RS, Brazil; ${ }^{3}$ Department of Animal Science, Universidade do Estado de Santa Catarina (UDESC), Chapecó, SC, Brazil; "S Section of Veterinary Pathology, Instituto Federal Catarinense (IFC), Concórdia, SC, Brazil

\begin{abstract}
This study was conducted to investigate the occurrence of oxidative stress in the heart tissue of rats infected with Trypanosoma evansi. Rats were divided into 2 groups (A and B) with 12 animals each, and further subdivided into 4 subgroups (A1 and A2, 6 animals/each; and B1 and B2, 6 animals/each). Animals in the groups B1 and B2 were subcutaneously inoculated with $T$. evansi. Thiobarbituric acid reactive substances (TBARS), superoxide dismutase activity (SOD), glutathione S-transferase activity (GST), reduced glutathione activity (GSH), and non-protein thiols (NPSH) in the heart tissue were evaluated. At day 5 and 15 post-infection (PI), an increase in the TBARS levels and a decrease in the SOD activity $(P<0.05)$ were observed. GSH and GST activities were decreased in infected animals at day $15 \mathrm{PI}(P<0.05)$. Considering the proper functioning of the heart, it is possible that the changes in the activity of these enzymes involved in the oxidative stress may be related, at least in part, in the pathophysiology of rats infected with $T$. evansi.
\end{abstract}

Key words: Trypanosoma evansi, "surra", thiobarbituric acid reactive substance, superoxide dismutase, oxidative stress

\section{INTRODUCTION}

Trypanosoma evansi is the etiologic agent of the disease known as "Surra" or "Mal das Cadeiras" in horses that affects domestic livestock and wildlife [1]. Trypomastigotes are transferred from one host to another through blood-sucking insects, i.e., mechanical transmission [2]. Many clinical signs are shown by animals infected with T. evansi, as well as cardiovascular disorders. T. evansi-infected rats have shown increased levels of biomarkers of cardiac function such as creatine kinase, creatine kinase fraction $\mathrm{MB}$, lactate dehydrogenase, and plasmatic myoglobin, as well as changes in cardiac cytosolic and mitochondrial creatine kinase and in the respiratory chain complex, in addition to mild multifocal lymphoplasmacytic inflammatory infiltration and necrosis [3].

Oxidative stress is the result of imbalances in cellular redox regulation and the inability of the antioxidant defense system

\footnotetext{
- Received 2 June 2015, revised 13 October 2015, accepted 4 November 2015.

*Corresponding author (matheusd.biomed@yahoo.com.br; sgmonteiro@uol.com.br) () 2016, Korean Society for Parasitology and Tropical Medicine

This is an Open Access article distributed under the terms of the Creative Commons Attribution Non-Commercial License (http://creativecommons.org/licenses/by-nc/4.0) which permits unrestricted non-commercial use, distribution, and reproduction in any medium, provided the original work is properly cited.
}

to regulate reactive oxygen species (ROS) [4]. Many animal studies have shown a critical role of ROS in maintaining cellular homeostasis and in regulating intracellular signaling acting as a redox messenger. Nevertheless, excessive ROS can lead to the accumulation of free radicals which induces oxidative damage of membrane lipids, genes, protein, nucleic acid, and ultimately leading to cell death $[5,6]$. This process causes oxidation of biomolecules with consequent loss of its biological functions and/or homeostatic imbalance and tissue injury [7].

Oxidative stress is a mechanism of pathogenicity in animals infected with T. evansi. According to Wolkmer et al. [8], T. evan$s i$ infection in rats is related to the oxidative stress due to oxidative damage in the erythrocyte's membranes. Others have reported that there was disorder of oxidant/antioxidant levels in the blood of camels and horses infected with T. evansi $[9,10]$. Recently, Baldissera et al. [11] reported that there was disorder of oxidant/antioxidant levels in the liver and kidney of rats infected with T. evansi, characterized by increased lipid peroxidation, decreased enzymatic activity of catalase and decreased levels of thiol groups (sulfhydryl). However, oxidative damage in the heart tissue was not evaluated during T. evansi infections.

Various studies have suggested that alterations in mitochondrial respiratory chain complex activity are one of the major 
systems in the myocyte for reactive oxygen species. The respiratory chain complex is recognized as prime sites for electron leakage to molecular oxygen, resulting in free radical generation in mitochondria [12,13]. Researchers have shown changes in complex II and IV of the respiratory cardiac chain in rats infected with T. evansi at days 5 and 15 post infection (PI), associated with histological lesions in the heart [3]. Therefore, the aim of this study was to evaluate occurrence of oxidative stress in the heart of rats experimentally infected with T. evansi.

\section{MATERIALS AND METHODS}

\section{T. evansi isolate and animals}

T. evansi isolate used in this study was originally isolated from a naturally infected dog [14] and has been maintained cryopreserved in liquid nitrogen. Initially, 1 rat (R1) was infected intraperitoneally with blood (cryopreserved in liquid nitrogen) containing $10^{6}$ parasites to obtain a large number of parasites for the experimental group of this study.

Female 60-day-old Wistar rats $(\mathrm{n}=24)$, conventional heterogenic outbred strain, weighing an average of 190-200 g, were used in this study. They were kept in cages, housed on a light/ dark cycle of $12 \mathrm{hr}$ in an experimental room with controlled temperature and humidity $\left(23 \pm 1^{\circ} \mathrm{C}\right.$ and $70 \%$, respectively). Animals were fed with commercial feed and water ad libitum. All animals were kept in their cages for a period of 15 days of adaptation.

\section{Experimental design, parasitemia estimation, and sample collection}

The animals were divided into 2 groups (A and B, 12 animals/each group), and further subdivided into 4 subgroups (A1 and A2, 6 animals/each; and B1 and B2, 6 animals/each). Animals in the groups B1 and B2 were inoculated subcutaneously with $0.06 \mathrm{ml}$ of blood from a rat (R1) containing $10^{6}$ trypanosomes (day 0).

Fresh peripheral blood from the coccygeal vein of rat tails was examined daily for parasitemia scoring degree after stained by the Romanowsky method. Slides were examined at a magnification of $\times 1,000$ according to the method described by Da Silva et al. [15].

On day 5 PI (subgroups A1 and B1) and day 15 PI (subgroups A2 and B2), the animals were humanely sacrificed for sample collection by decapitation without anesthetics. Heart fragments were collected and kept under refrigeration for bio- chemical analyses. Heart fragments were also used for histopathological analyses.

\section{Tissue preparation}

Heart fragments were placed in a buffered ( $\mathrm{pH}$ 7.4) solution containing $20 \mathrm{mM}$ sodium phosphate and $140 \mathrm{mM} \mathrm{KCl}$ buffer. Later, heart fragments were homogenized $(1: 10 \mathrm{w} / \mathrm{v})$ using a Potter-Elvehjem glass homogenizer and centrifuged at $800 \mathrm{~g}$ for $10 \mathrm{~min}$ at $4^{\circ} \mathrm{C}$. The supernatant was collected and frozen at $-80^{\circ} \mathrm{C}$ for no more than 3 weeks until determination of oxidative stress parameters and protein levels.

\section{Thiobarbituric acid reactive substances measurement (TBARS)}

TBARS was measured according to the technique described by Ohkawa et al. [16]. TBARS measures mainly malondialdehyde (MDA), a product of lipoperoxidation caused mostly by hydroxyls free radicals. Briefly, samples and reagents were placed into glass tubes in the following order: $200 \mu \mathrm{l}$ of homogenized tissue supernatant, $200 \mu \mathrm{l}$ of $8.1 \%$ SDS (sodium dodecyl sulphate), $500 \mu \mathrm{l}$ of $2.5 \mathrm{M}$ acetic acid in aqueous solution (v/v) pH 3.4, $500 \mu \mathrm{l}$ of $0.8 \%$ thiobarbituric acid (TBA), and $100 \mu \mathrm{l}$ of distilled water. The mixture was mixed, and the reaction was carried out in a boiling water bath for $1 \mathrm{hr}$. TBARS were determined by the absorbance at $532 \mathrm{~nm}$ and were expressed as malondialdehyde equivalents (nmol MDA/ml).

\section{Superoxide dismutase (SOD) activity}

The measurement of SOD activity was based on the inhibition of the radical superoxide reaction with adrenalin as described by McCord and Fridovich [17]. In this method, SOD present in the sample competes with the detection system for radical superoxide. One SOD unit is defined as the amount of enzyme able to slow down the speed of adrenalin oxidation in $50 \%$. The oxidation of adrenalin leads to the formation of a colored product adrenochrome that might be detected by spectrophotometry. SOD activity was determined by measuring the speed of adrenochrome formation observed at $480 \mathrm{~nm}$ in a reaction medium containing glycine- $\mathrm{NaOH}(50 \mathrm{mM}, \mathrm{pH}$ $10.0)$ and $1 \mathrm{mM}$ adrenalin. Specific activity was expressed as SOD units per mg of protein.

\section{Glutathione S-transferase (GST) assay}

GST activity was measured as described by Habig et al. [18]. Freshly prepared cell lysate $(25-50 \mu \mathrm{l})$ was mixed in a cuvette 
with $1 \mathrm{ml}$ of GST assay buffer containing either $1 \mathrm{mM}$ chloro-2,4-dinitrobenzene (CDNB) and $1 \mathrm{mM}$ reduced glutathione [GSH] or $1 \mathrm{mM}$ 4-nitrobenzylchloride and $5 \mathrm{mM} \mathrm{GSH}$ in $0.11 \mathrm{M}$ sodium phosphate ( $\mathrm{pH}$ 6.5), and incubated at room temperature. The absorbance (CDNB $340 \mathrm{~nm}$; 4-nitrobenzylchloride at $310 \mathrm{~nm}$ ) was measured at timed intervals, and the specific GST activity of each lysate was determined from the change in absorbance considering measurement timing (min) and amount of protein ( $\mu \mathrm{g})$. GST was calculated as nmol GSDNB per min per mg of protein.

\section{Reduced glutathione (GSH) content}

GSH is the most important non-enzymatic antioxidant present in the cell. GSH levels were measured according to Browne and Armstrong [19], which is based on the reaction of GSH with the fluorophore 0 -phthaldehyde (OPT), using the sample by deproteinization with metaphosphoric acid. Then, 150 $\mu \mathrm{l}$ of the sample was incubated with an equal volume of $0-$ phthaldehyde $\left(1 \mathrm{mg} / \mathrm{ml}\right.$ of methanol) by $15 \mathrm{~min}$ at $37^{\circ} \mathrm{C}$. Fluorescence was measured using excitation of $350 \mathrm{~nm}$ and emission of $420 \mathrm{~nm}$ wavelengths. Calibration curve was performed using standard GSH (1 mM), and tissue supernatant concentrations were expressed as nmol of GSH per mg of protein.

\section{Non-protein thiols (NPSH)}

Tissue non-protein thiols were determined as previously described by Ellman [20]. Briefly, an aliquot of the homogenized tissue supernatant (1:10 w/v) was diluted (1:1) with 10\% TCA, vortexed, and centrifuged at 2,000 g for $10 \mathrm{~min}$. Subsequently, the supernatant was mixed with $250 \mu \mathrm{M}$ of DNTB in a final volume of $2 \mathrm{ml}$, and the absorbance was read at $412 \mathrm{~nm}$. A cysteine solution was used as reference. NPSH were expressed as $\mu \mathrm{mol} \mathrm{SH} / \mathrm{g}$ of tissue.

\section{Protein levels}

The protein content was measured colorimetrically according to the Lowry method [21] using bovine serum albumin (1 $\mathrm{mg} / \mathrm{ml}$ ) as the standard solution.

\section{Histology}

Small sections of the left ventricle were collected and stored in 10\% buffered formalin solution. Sagittal sections of every 3 $\mathrm{mm}$ were obtained and stained with hematoxylin and eosin (H-E).

\section{Statistical analyses}

The data set was tested for normality by the KolmogorovSmirnov test, and transformed into logarithm when they were not normally distributed. Then, determination of TBARS, SOD, GST, GSH, and NPSH levels was subjected to bilateral Student's $t$-test for independent samples to verify the differences on the data set. Results were considered statistically different when $P<0.05$.

\section{RESULTS}

\section{T. evansi infection}

T. evansi was detected in peripheral blood of all infected rats at day 2-3 PI. Infected animals showed an average of 14 trypanosomes/field at 5 day PI. Fifteen days PI, infected animals had an average of 20 trypanosomes/field. The uninfected groups remained clinically healthy throughout the experimental period (Fig. 1).

\section{TBARS levels}

Cardiac TBARS values are shown in Fig. 2A. The TBARS levels increased $(P<0.05)$ in the infected group on days 5 and 15 PI compared to the control group.

\section{SOD activity and NPSH levels}

Superoxide dismutase activities in the heart are shown in Fig. 2B. SOD activity was decreased $(P<0.05)$ in the infected group on days 5 and 15 PI compared to the control group. There was no difference between the groups regarding NPSH levels $(P>0.05$; data not shown).

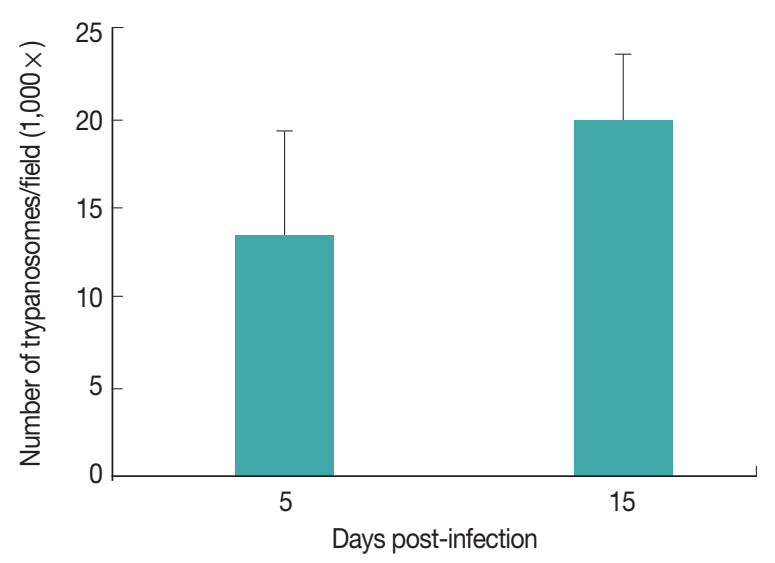

Fig. 1. Parasitemia levels of rats infected with Trypanosoma evansi on days 5 and 15 post-infection (PI). 
A TBARS

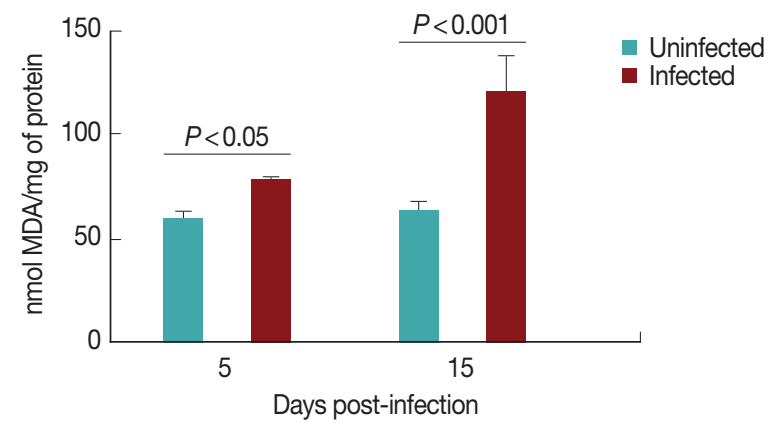

B SOD activity

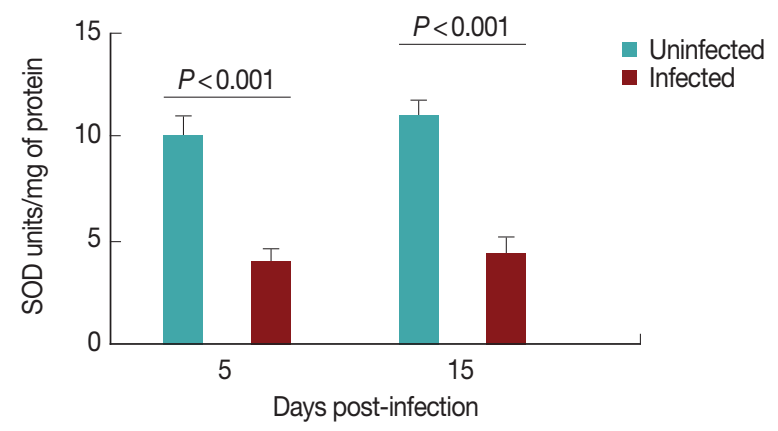

Fig. 2. TBARS levels (A) and superoxide dismutase activity (B) in rats experimentally infected with $T$. evansi compared to uninfected controls on days 5 and 15 PI. Statistical analysis was performed by the Student's $t$-test $(P<0.05)$.

\section{GST assay and GSH content}

Cardiac GST results are shown in Fig. 3A. GST activity was significantly decreased $(P<0.05)$ in the infected group on day 15 PI. There was no difference between the groups on day 5 PI $(P>0.05)$. Fig. 3B shows the results for GSH content in the heart. GSH activity was significantly decreased $(P<0.05)$ in the infected group on day 15 PI. There was no difference between groups on day 5 PI $(P>0.05)$.

\section{Histology}

T. evansi-infected rats showed mild alterations on day 15 PI (Fig. 4), where only mild cardiac inflammatory infiltrates were observed. Acidophilic cytoplasms and nuclei pyknosis in cardiac cells, as well as tissue necrosis were also observed.

\section{DISCUSSION}

Studies conducted by Baldissera et al. [3] and El-Deeb and Elmoslemany [22] have shown an increase in indicators of cardiac injury, such as creatine kinase (CK), creatine kinase
A GST assay

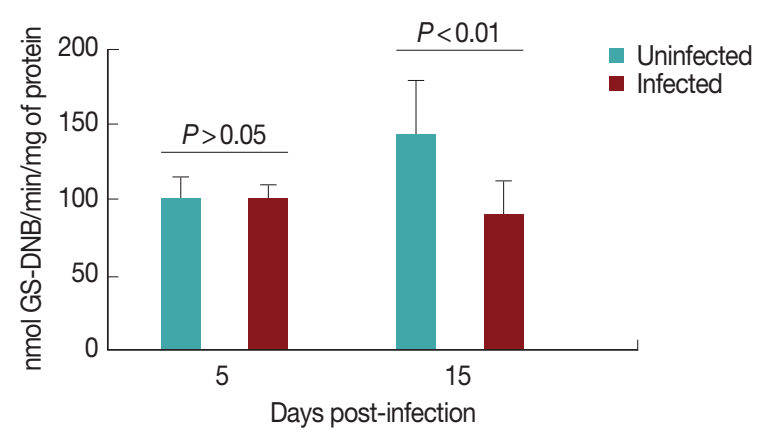

B GSH content

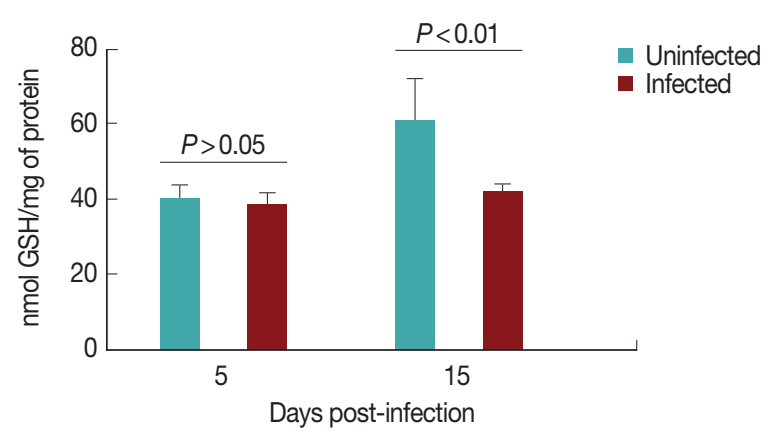

Fig. 3. Glutathione S-transferase (A) and reduced glutathione (B) activities in rats experimentally infected with $T$. evansi compared to uninfected controls on days 5 and $15 \mathrm{PI}$. Statistical analysis was performed by the Student's $t$-test $(P<0.05)$.

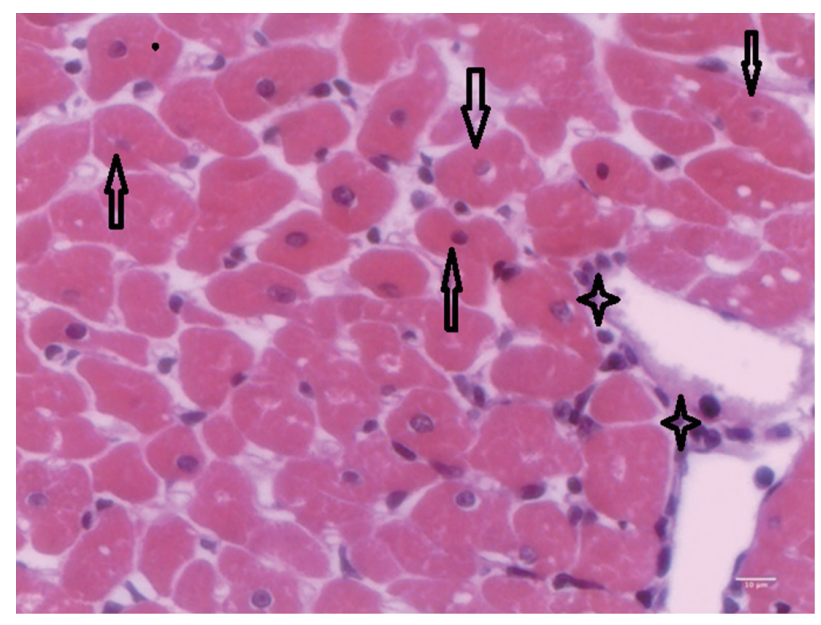

Fig. 4. Heart of rats infected with $T$. evansi showing mild inflammatory cell infiltrates (asterisk) and cardiac cells with acidophilic cytoplasm and pyknotic nuclei (arrows; ×400).

fraction $\mathrm{MB}(\mathrm{CK}-\mathrm{MB})$, myoglobin, and lactate dehydrogenase (LDH) in plasma of T. evansi-infected rats, and increase in cardiac troponin I (CTnI), CK-MB, and CK in serum of infected camels, respectively. According to Ansley and Wang [23], one 
of the mechanisms of cardiac injury is the oxidative stress system. Oxidative stress increases in cases of chronic heart failure. The oxidative stress was evaluated in plasma and sera; howev$\mathrm{er}$, it has not been evaluated yet in the cardiac tissue.

In the present study, oxidative stress was evident as indicated by higher levels of lipid peroxidation biomarker (MDA) and inhibition of antioxidant enzymes due to high levels of free radicals in T. evansi-infected rats. The accumulation of MDA in tissues is indicative of the extent of free radical generation, oxidative stress, and damage [24]. Earlier studies have demonstrated higher levels of MDA in mice infected with Trypanosoma brucei [25], in sera of camel and horses infected with T. evansi $[9,10,22]$, and in the liver of rats infected with T. evansi [11].

The process of oxidative stress is a result of an imbalance between oxidant and antioxidant compounds due to the excessive generation of free radicals or due to a lower removal speed of the latter, and there is abundant circumstantial evidence that oxidative reaction contributes to cardiovascular diseases $[7,26]$. It was reported that oxidative stress might be implicated in several effects relevant to the pathophysiological mechanisms of heart failure. Results published by Baldissera et al. [3] have shown an increase in plasma levels of creatine kinase, MB-creatine kinase fraction, myoglobin, and lactate dehydrogenase, important markers of cardiac injury. According to Ansley and Wang [23], markers of lipid peroxidation are significantly increased in cases of irreversible myocardial injuries, as observed in this study.

The action of the enzyme superoxide dismutase (SOD) is a defense mechanism against reactive oxygen species (ROS). The present study reported for the first time lower levels of SOD in the heart of T. evansi-infected rats on days 5 and 15 PI compared to uninfected animals. The same results were found by El-Deeb and Esmoslemany [22] in sera of camels infected with T. evansi. According to Saleh et al. [9], lower SOD activity might be related to its depletion as free radical scavengers during the oxidative stress in camels infected with T. evansi. On the other hand, rats infected with T. evansi showed activation of SOD activity in total blood on days 5 and 15 PI [27].

This is the first study reporting changes in GST and reduced GSH activities in rats infected with T. evansi on days 5 and 15 PI. Studies conducted by Anschau et al. [28] reported decrease of GSH activities in blood of T. evansi-infected rats, but they have not reported differences in GST activity in the heart, as observed in our study. GSH is the major intracellular redox buffer and plays a key role in cellular protection against oxida- tive damage [29], being recognized as a marker of cell viability and a reducer of oxidative damage [30].

Studies conducted by El-Deeb and Esmoslemany [22] using camels infected with T. evansi have suggested a correlation between increased seric levels of cardiac injury biomarkers and oxidative stress. The damage of cellular proteins and membranes is a mechanism through which myocardial oxidative stress may compromise cardiac function. El-Deeb and Esmoslemany [22] reported increased serum malondialdehyde and erythrocyte malondialdehyde levels in infected camels, and consequently, increased seric levels of CTnI, CK, and CK-MB.

It has been reported that ROS might be present in several pathophysiological mechanisms of chronic heart failure. Thus, based on these results, we believe that the oxidative stress observed by increased lipid peroxidation and decreased enzymatic activities of SOD, GSH, and GST may lead to cardiac injury and contributes to the pathophysiology of the infection caused by T. evansi.

\section{ACKNOWLEDGMENT}

The procedures were approved by the Animal Welfare Committee of the Universidade do Estado de Santa Catarina under protocol number 01.27.14.

\section{CONFLICT OF INTEREST}

We have no conflict of interest related to this work.

\section{REFERENCES}

1. Maudlin I, Holmes PH, Miles MA. The Trypanosomiases. Wallingford, UK. CABI Publishing Co. 2004, p 640.

2. Hoare CA. The Trypanosomes of Mammals, a Zoological Monograph. Oxford, UK. Blackwell. 1972.

3. Baldissera MD, Rech VC, Grings $M$, Gressler LT, Vaucher RA, Schwertz CI, Mendes RE, Leipnitz G, Stefani LM, Monteiro SG, Da Silva AS. Enzymatic activities linked to cardiac energy metabolism of Trypanosoma evansi-infected rats and their possible functional correlations to disease pathogenesis. Parasitology 2015; 142: 1163-1170.

4. Betteridge DJ. What is oxidative stress? Metabolism 2000; 49: 3-8.

5. Thannickal VJ, Fanburg BL. Reactive oxygen species in cell signaling. Am J Physiol Lung Cell Mol Physiol 2000; 279: 1005-1028.

6. Circu ML, Aw TY. Reactive oxygen species, cellular redox systems, and apoptosis. Free Radic Biol Med 2010; 48: 749-762. 
7. Halliwell B, Whiteman M. Measuring reactive species and oxidative damage in vivo and in cell culture: how should you do it and what do the results mean? Br J Pharmacol 2004; 142: 231255.

8. Wolkmer P, da Silva AS, Traesel CK, Paim FC, Cargnelutti JF, Pagnoncelli M, Picada ME, Monteiro SG, Lopes ST. Lipid peroxidation associated with anemia in rats experimentally infected with Trypanosoma evansi. Vet Parasitol 2009; 28: 41-46.

9. Saleh MA, Al-Salahy, MB Sanousi SA. Oxidative stress in blood of camels (Camelus dromedaries) naturally infected with Trypanosoma evansi. Vet Parasitol 2009; 162: 192-199.

10. Ranjithkumar M, Kamili NM, Saxena A, Dan A, Dey S, Raut SS. Disturbance of oxidant/antioxidant equilibrium in horses naturally infected with Trypanosoma evansi. Vet Parasitol 2011; 180: 349-353.

11. Baldissera MD, Oliveira CB, Rech VC, Rezer JFP, Sagrillo MR, Alves MP, da Silva, APT, Leal DBR, Boligon AA, Athayde ML, Da Silva AS, Mendes RE, Monteiro SG. Treatment with essential oil of Achyrocline satureioides in rats infected with Trypanosoma evansi: relationship between protective effect and tissue damage. Pathol Res Pract 2014; 210: 1068-1074.

12. Lesnefsky EJ, Gudz TI, Migita CT, Ikeda-Saito M, Hassan MO, Turkaly PJ, Hoppel CL. Ischemic injury to mitochondrial electron transport in the aging heart: damage to the iron-sulfur protein subunit of electron transport complex III. Arch Biochem Biophys 2001; 385: 117-128.

13. Chen Q, Vazquez EJ, Moghaddas S, Hoppel CL, Lesnefsky EJ. Production of reactive oxygen species by mitochondria: central role of complex III. J Biol Chem 2003; 278: 36027- 36031.

14. Colpo CB, Monteiro SG, Stainki DR, Colpo ETB, Henriques GB. Natural infection by Trypanosoma evansi in dogs. Ciênc Rural 2005; 35: 717-719.

15. Da Silva AS, Doyle RL, Monteiro SG. Métodos de contenção e confecção de esfregaço sanguíneo para pesquisa de hemoparasitas em ratos e camundongos. F Med Vet Zoot Agro 2006; 13: 8387.

16. Ohkawa H, Ohishi N, Yagi K. Assay for lipid peroxides in animal tissues by thiobarbituric acid reaction. Anal Biochem 1979; 95: 351-358.

17. McCord JM, Fridovich I. Superoxide dismutase: an enzymatic function for erythrocuprein (hemocuprein). J Biol Chem 1969;
244: 6049-6055.

18. Habig WH, Pabst MJ, Jakoby WB. Glutathione S-transferase. The first enzymatic step in mercapturic acid formation. J Biol Chem 1974; 249: 7130-7139.

19. Browne RW, Armstrong D. Reduced glutathione and glutathione disulfide. Methods Mol Biol 1998; 108: 347-352.

20. Ellman GL. Tissue sulfhydryl groups. Arch Biochem Biophys 1959; 82: 70-77.

21. Lowry OH, Rosebrough NJ, Farr AL, Randall RJ. Protein measurement with the Folin phenol reagent. J Biol Chem 1951; 193: 265-267.

22. El-Deeb WM, Elmoslemany AM. Cardiac and oxidative stress biomarkers in Trypanosoma evansi infected camels: diagnostic and prognostic prominence. Parasitology 2015; 12: 1-6.

23. Ansley DM, Wang B. Oxidative stress and myocardial injury in the diabetic heart. J Pathol 2013; 229: 232-241.

24. Gutteridge JM. Lipid peroxidation and antioxidants as biomarkers of tissue damage. Clin Chem 1995; 41: 1819-1828.

25. Igbokwe I, Esievo K, Saror D, Obagaiye O. Increased susceptibility of erythrocytes to in vitro peroxidation in acute Trypanosoma brucei infection of mice. Vet Parasitol 1994; 55: 279-286.

26. Pashkow FJ. Oxidative stress and inflammation in heart disease: do antioxidants have a role in treatment and/or prevention? Int J Inflam 2011; 2011: 514623.

27. Da Silva AS, Paim FC, Santos RCV, Sangoi MB, Moresco RN, Lopes STA, Jaques JA, Baldissarelli, J, Morsch VM, Monteiro SG. Nitric oxide level, protein oxidation and antioxidant enzymes in rats infected by Trypanosoma evansi. Exp Parasitol 2012; 132: 166170.

28. Anschau V, Dafré AL, Perin AP, Iagher F, Tizatto MV, Miletti LC. Glutathione and iron at the crossroad of redox metabolism in rats infected by Trypanosoma evansi. Parasitol Res 2013; 112: 23612366.

29. Fang YZ, Yang S, Wu G. Free radicals, antioxidants and nutrition. Nutrition 2002; 18: 872-879.

30. Netto LE, De Oliveira MA, Monteiro G, Demasi AP, Cussiol JR, Discola KF, Demasi M, Silva GM, Alves SV, Faria VG, Horta BB. Reactive cysteine in proteins: protein folding, antioxidant defense, redox signaling and more. Comp Biochem Physiol C Toxicol Pharmacol 2007; 146: 180-193. 